\title{
The Effects of Unilateral Environmental Regulations in a World with Capital Mobility and Trading Costs
}

\author{
Arsène Rieber ${ }^{\mathrm{a}}$ and Thi Anh-Dao Tran ${ }^{\mathrm{b} *}$ \\ ${ }^{a}$ University of Rouen, France \\ ${ }^{b}$ University of Rouen and University of Paris 13, France
}

\begin{abstract}
Our paper discusses the management of global pollution issues in a North-South economic geography model with capital mobility and trading costs. We first show that a unilateral environmental policy adopted by the developed country drives the industrial firms out of the region and lowers real income. However, the ecological dumping argument has only found partial theoretical support as the Northern larger market still attracts firms. More importantly, the total effect on the environment appears ambiguous: due to multiple interactions at work, globalization can make pollution even worse. These outcomes provide arguments for international cooperation. However, although efficient in reducing global pollution, this second option hurts the South both in terms of industrial relocation and real income.
\end{abstract}

JEL classifications: F12, 019, R38

Keywords: globalization, international environmental issues, ecological dumping, North-South, economic geography

\section{Introduction}

Economic integration through globalization of the world economy has reinforced the interdependence between individual nations, and this may drastically change the

\footnotetext{
* Corresponding author: University of Rouen, Department of Economics, 3, Avenue Pasteur F-76186 Rouen Cedex 1 (FRANCE). Fax number: +33 (0)2 327696 63. Email: thianh-dao.tran@univ-rouen.fr

This paper is based on a study undertaken by the Center for Analysis and Research in Economics (CARE) in cooperation with the Institute of World Economics and Politics (IWEP, Vietnamese Academy of Social Sciences, Vietnam). The authors are grateful for financial support from the French Ministry of Foreign Affairs through the Fonds de Solidarité Prioritaire (FSP project in Social Sciences). The views expressed in this paper are solely those of the authors and should not in any way be attributed to the above institutions.

We thank Prof. Ngo Van Long and an anonymous referee for their helpful comments and review of the manuscript. We are also indebted to Katrin Millock for assistance on earlier drafts of this paper. Any errors or omissions are the authors' responsibility.
} 
efficiency of national policy instruments. Environmental policy-making aptly illustrates this new perception of a changing world. Under the assumption of productive factor immobility, standard theory argues that the optimal environmental policy consists of "internalizing" pollution externalities by equalizing the marginal disutility of pollution to the marginal cost of pollution abatement. However, in response to the international mobility of capital, competitiveness concerns have gained raising interest in all governments. Environmentalists are then afraid that the individual pursuit of this objective can enter in conflict with the safeguarding of environmental resources. Notably, "free rider" behavior can lead to excessively low standards across the world, thereby involving irreversible environmental damages on a global level. In the literature, this argument has been referred to as the "race to the bottom".

The interaction between trade and the environment has obviously been a subject of theoretical work. A first range of models has investigated this relationship by relying on conventional determinants of comparative advantage. In particular, Grossman and Krueger (1993) contributed to the trade and environment debate which took place during the implementation of the North-American Free Trade Agreement (NAFTA) by pointing to the prevalence of what they call the «composition effect». ${ }^{1}$ According to the classical trade theory based on differences in factor endowments, developed countries have a comparative advantage in capital-intensive industries that are inherently more polluting. In contrast, countries with relatively weak income will specialize in labor-intensive production which is by nature less polluting. Since differences in environmental standards tend to reflect differences in incomes, developed countries will apply tougher regulations, so that regional agreements and more generally international trade will imply an industrial redistribution favorable to the environment. This argument has been afterwards referred to as the "factor endowments hypothesis".

By considering pollution as an additional production factor, Low and Yeats (1992) developed a rather opposite line of argument which corresponds to the "pollution haven hypothesis". According to them, developing countries have an apparent comparative advantage in polluting activities precisely because of laxer environmental regulations. Trade liberalization, by increasing competitive pressures on national regulations, will be harmful for the environment in accordance with the classical pattern of comparative advantage. $^{2}$

In this regard, our paper attempts to develop a theoretical analysis of the NorthSouth tension at work in the environmental debate. To do this, we extend the traditional analysis of the interaction between trade and the environment by taking into account the

\footnotetext{
${ }^{1}$ Antweiler et al (2001) presents a substantive review of the various interacting elements which drive the environmental consequences of international trade: the composition effect, the scale effect, and the technique effect.

${ }^{2}$ Copeland and Taylor $(1997,2004)$ confront the two opposite hypotheses in a coherent trade model. They conclude that the trade and environment relationship is greatly conditioned by the income gap between the North and the South.
} 
international mobility of capital. ${ }^{3}$ While earlier theoretical literature has argued that trade flows primarily impact the environment by factor endowment considerations, the new economic geography approach initiated by Krugman (1991) put stress on the impact of factor mobility on trade. Under increasing returns and imperfect competition, differences in environmental policies may then have some effect on international trade through factor mobility. By bridging the gap between trade, factor mobility and the environment, our contribution here is to investigate the location decisions of firms under North-South exogenous asymmetry in capital endowments and environmental regulations.

The rest of the paper is organized as follows. Section 2 describes our theoretical model. We then examine international environmental issues in two steps: first, Section 3 looks at whether the eco-dumping assertion is conclusive by analyzing the outcomes of unilateral environmental policy adopted by the developed region. More precisely, we assess this non-cooperative policy both in terms of efficiency on global pollution abatement and in terms of income and spatial allocation of industry. We also evaluate how globalization of the world economy affects the various interactions at work. Then, Section 4 turns to investigate in the same manner the outcomes of cooperative environmental policy at the international level. Finally, Section 5 concludes and summarizes the main results.

\section{A Model of Economic Geography}

\subsection{The analytical framework}

In order to analyze the eco-dumping argument in a geography model, we rely on Martin and Rogers (1995) whose model has been generalized in Baldwin et al (2003) in the so-called "footloose capital" model. This denomination refers to a process of spatial dynamics which is conducted by capital mobility according to profit differentials across regions. ${ }^{4}$

We consider a world composed of two regions: North and South (respectively subscript $\mathrm{N}$ and $\mathrm{S}$ ). The two regions are endowed with an identical total labor supply L. In each economy there are two sectors: a traditional sector (subscript T) and manufacturing (subscript M). The traditional sector is perfectly competitive and produces a homogeneous good under constant returns to scale. It is assumed that this good is costlessly tradable. The location of the traditional activity is predetermined by the location of the immobile factors. The industrial sector produces differentiated goods

\footnotetext{
${ }^{3}$ Pflüger (2001) relies on the same theoretical model of monopolistic competition with capital mobility to study ecological dumping. But he considers local pollution externalities and focuses his analysis on the properties of optimal emission taxes under symmetric countries. In the same vein, Zeng and Zhao (2006) formalize local pollution with cross-sector externalities. They conclude that the pollution haven effect may be exaggerated in the literature.

${ }^{4}$ The main advantage of such a framework, compared to the traditional economic geography models with catastrophic agglomeration (Krugman, 1991; Krugman and Venables, 1995), is that it affords an analytically tractable solution for the spatial equilibrium. In return, the footloose capital model cuts the circular and cumulative causality that induces a self-reinforcing agglomeration process by assuming that the mobile factor repatriates all of its earnings to its country of origin.
} 
under increasing returns and monopolistic competition. They are tradable at cost in Samuelson's iceberg form: by denoting $\tau$ trade costs, the idea is that only a fraction $1 / \tau$ of one unit of an industrial variety arrives on the export market. Trade costs on the global markets are thus proportional to the parameter $\tau$.

Two productive factors are used in the industrial sector: labor L and physical capital K. More specifically, we assume that each industrial variety requires one unit of capital. ${ }^{5}$ Hence, the number of differentiated products is determined by the amount of capital available in the two regions. By denoting $n_{i}$ the number of available varieties in region $i$ (ie the number of industrial firms located in region $i$ ) and $K_{i}$ the capital endowment of region $i$, we can write that: $n_{N}+n_{S}=K_{N}+K_{S}$.

Contrary to the traditional sector, industrial firms can freely move across regions. Spatial dynamics in the model are then driven by capital mobility in response to profit differentials. In contrast, labor is nationally mobile but internationally immobile. Denoting by $s_{n}$ North's share of world industry $\left(s_{n}=n_{N} /\left(n_{N}+n_{S}\right)\right)$ and $\pi_{i}$ the reward to capital in region $i$, the spatial dynamics are described in the following way:

$$
\dot{s_{n}}=\left(\pi_{N}-\pi_{S}\right)\left(1-s_{n}\right) s_{n}
$$

where, in addition to a core-periphery solution $\left(s_{n}=0\right.$ or $\left.s_{n}=1\right)$, an interior equilibrium will result from an arbitrage condition that equalizes capital's rates of return across regions. The industrial structure of our two regions $\mathrm{N}$ and $\mathrm{S}$ is consequently endogenous and, because physical capital can be separated from its owners, we must therefore distinguish the capital endowment of a region from the number of industrial firms located in this region. More precisely, we must distinguish the share of world capital owned by North (we denote this as $s_{K}=K_{N} /\left(K_{N}+K_{S}\right)$ ) from the share of industrial firms located in North $\left(s_{n}\right)$.

Turning to greenhouse gas emissions, the industrial sector exploits a basic technology characterized by an emission coefficient $a$. Every firm can cut its polluting emissions but it incurs an abatement cost. Indeed, any emission standard $\beta_{i} a$ imposed by the authorities of region $i$ (with $0<\beta_{i}<1$ ) requires an additional fixed cost $v_{i}$ (the environmental cost $v_{i}$ is measured in units of labor). Moreover, we assume that this additional fixed cost is inversely proportional to the effort of pollution abatement, so that:

$$
v_{i}=v\left(\beta_{i}\right) \text { with } v^{\prime}<0 \text { and } v(1)=0
$$

To describe the government's environmental policy, we assume that it seeks to control pollution and imposes an exogenous level of polluting emissions ${ }^{6}$ resulting from local or international agreements. As our main purpose here is not to compare the efficiency of various policy instruments of environmental regulation, we restrict

\footnotetext{
${ }^{5}$ Since each unit of capital can be used to produce one industrial variety, the reward to capital would be bid up to the point where it equals operating profit (see Baldwin et al, 2003).

${ }^{6}$ In response to the difficulty in determining the optimal level of pollution, we assume as in Baumol and Oates (1971) an exogenous environmental policy. By this, we choose to ignore the strategic dimension of environmental policy under imperfect competition (Ulph, 1996a; 1996b; 1997).
} 
our discussion to the case of emission standards which, in contrast to environmental taxes, does not generate budget revenue ${ }^{7}$. Emission standards therefore circumvent the redistribution policy issue which might strongly condition the outcomes of our analysis and would move us away from our focus.

In the model, two assumptions describe North-South asymmetry:

1) Differences in incomes. We assume that capital is more abundant in North $\left(s_{K}>1 / 2\right)$, which means, as we will see henceforth, that North's income is higher than the Southern one.

2) Asymmetry in environmental regulations. Initially, the national environmental regulation is more stringent in $\operatorname{North}^{8}: \beta_{N}<\beta_{S}$. According to relation (2), this implies that the environmental cost supported by the Northern firms is higher than the one prevailing in South, $v_{N}>v_{S}$.

The technology used by a typical firm located in region $i$ is described by its cost function $\left(C T_{i}\right)$ :

$$
C T_{i}=\pi_{i}+w_{i} c x_{i}+w_{i} v_{i} \forall i=N, S
$$

where the variable cost involves $c$ units of labor per unit of output, $x_{i}$ is firm-level output in region $i$ and $w_{i}$ the nominal reward to labor in region $i$.

Industrial activity generates global pollution at the level:

$$
P=\int_{0}^{n_{N}+n_{S}} e_{j} d j=a\left(n_{N} \beta_{N} x_{N}+n_{S} \beta_{S} x_{S}\right)
$$

where $e_{j}$ denotes the level of polluting emissions by firm $j$.

In each region, the representative consumer has Cobb-Douglas tastes and preferences given by:

$$
U=C_{M}^{\mu} C_{T}^{1-\mu} \text { with } 0<\mu<1
$$

where $C_{T}$ and $C_{M}$ are respectively the consumption of the traditional good and that of a composite industrial good defined over a continuum of varieties of differentiated goods. Let $C_{j}$ be the consumption of each available variety $j$ and assume that the representative consumer has a preference for variety in industrial goods, then $C_{M}$ is defined by a constant-elasticity-substitution (CES) function:

$$
C_{M}=\left(\int_{j=0}^{n_{N}+n_{S}} C_{j}^{1-1 / \sigma} d j\right)^{\left(\frac{\sigma}{\sigma-1}\right)}
$$

\footnotetext{
${ }^{7}$ Indeed, the efficiency of environmental tax policy depends upon the distribution of tax revenue and how it is spent (Rauscher, 1995; Wilson, 1996). For a discussion on the efficiency of the various policy instruments of environmental regulation under monopolistic competition, see Chiroleu-Assouline et al (2003).

${ }^{8}$ This assumption becomes an outcome in the case of local pollution issues when the environmental policy is endogenous: as environmental quality is a normal good, the richer region will apply stricter environmental standards (Copeland and Taylor, 1994; 1995).
} 
where $\sigma>1$ is the constant elasticity of substitution between any two varieties, and $(1-1 / \sigma)$ the intensity of the preference for variety in industrial goods.

Combining relations (5) and (6), we can express the indirect utility function of the representative consumer in region $i$ :

$$
V_{i}=\frac{E_{i}}{G_{i}} \quad G_{i}=p_{i T}^{1-\mu}\left(\int_{j=0}^{n_{N}+n_{S}} p_{i j}^{1-\sigma} d j\right)^{\left(\frac{-\mu}{1-\sigma}\right)} \quad \forall i=N, S
$$

where $E_{i}$ is the region-specific expenditure (ie. income, as there is no taxation and no savings in this model), $G_{i}$ is the price index in region $i, p_{i T}$ is the price of the traditional good in region $i, p_{i j}$ is the consumer price of industrial variety $j$ in region $i$.

The level of income in region $i$ is the sum of labor and capital income:

$$
E_{i}=\pi_{i} K_{i}+w_{i} L \quad \forall i=N, S
$$

Utility maximization yields a constant division of expenditure between the consumption of traditional and composite industrial goods:

$$
C_{i T}=(1-\mu) E_{i} \quad C_{i M}=\mu E_{i} \quad \forall i=N, S
$$

where $\mu$ is the expenditure share on industrial varieties.

Utility maximization also implies that the demand function for industrial variety $j$ in region $i$ is:

$$
C_{i j}=\frac{p_{i j}^{-\sigma} \mu E_{i}}{\int_{j=0}^{n_{N}+n_{S}} p_{i j}^{1-\sigma} d j} \forall i=N, \quad S
$$

Turning to $p_{i}$, the producer price for an industrial variety $j$ in region $i$, it results from profit maximization under monopolistic competition which sets prices as constant markups on marginal costs. Moreover, recall that Samuelson's iceberg trade costs imply that prices on the export market $k$ are proportional to the parameter $\tau$. Thus:

$$
p_{i}=\frac{\sigma w_{i} c}{\sigma-1} \quad p_{k}=\frac{\tau \sigma w_{i} c}{\sigma-1} \quad \forall i, k=N, S \text { with } i \neq k
$$

Technology in the traditional sector is characterized by two simplifying assumptions without loss of generality: first, producing traditional goods requires only labor and second, it takes one unit of labor to make one unit of the traditional good. With those simplifying assumptions and choosing the traditional good to be the numeraire, profit maximization in the constant-returns sector combined with intersectoral mobility of 
labor imply that $w_{i}=1$. In addition, if we assume that the traditional good is produced in both regions, ${ }^{9}$ its costless trade ensures that $w_{N}=w_{S}=w=1$.

Thereafter, by normalizing the marginal cost of the increasing-returns sector to $c=1-1 / \sigma$ and replacing $w_{i}=1$, the pricing equation (11) becomes $p_{i}=1$ and $p_{k}=\tau$.

\subsection{Spatial allocation equilibrium and global pollution}

Using relations (3) and (11), we can derive the reward to capital in region $i$ :

$$
\pi_{i}=\left(p_{i} x_{i} / \sigma\right)-v_{i}
$$

Since total world spending on industrial varieties equals $\mu E_{w}$ and since an interior equilibrium $\left(0<s_{n}<1\right)$ is defined by equalizing capital's rates of return across regions, the long-run reward to capital will be: $\pi^{*}=\alpha E_{w}-v_{n} s_{n}-v_{S}\left(1-s_{n}\right)$ with $\alpha=\mu / \sigma<1$.

Meanwhile, by normalizing the world capital endowment $K_{w}$ to 1 , we derive the expression for world income: $E_{w}=2 L+\pi^{*}$. This can be also rewritten as:

$$
E_{w}=\frac{2 L-v_{N} s_{n}-v_{S}\left(1-s_{n}\right)}{(1-\alpha)}
$$

Employing relation (12), we can define the long-run equilibrium expression of capital's reward as:

$$
\pi^{*}=\frac{2 \alpha L-v_{N} s_{n}-v_{S}\left(1-s_{n}\right)}{(1-\alpha)}
$$

Condition $\pi^{*} \geq 0$ implies that:

$$
v_{N} s_{n}+v_{S}\left(1-s_{n}\right) \leq 2 \alpha L
$$

Defining $s_{E}=E_{N} / E_{w}$ as North's share of world expenditure, we can use (8), (12) and (13) to get:

$$
s_{E}=\frac{(1-\alpha)}{2 L-v_{N} s_{n}-v_{S}\left(1-s_{n}\right)}\left(L-v_{N} s_{n} s_{K}-v_{S} s_{K}\left(1-s_{n}\right)\right)+\alpha s_{K}
$$

The above "market-size condition" describes the impact of endowment shares of world capital $\left(s_{K}\right)$ on the relative market size $\left(s_{E}\right)$. In contrast to Baldwin et al (2003), expression (15) implies that the spatial distribution of industry $\left(s_{n}\right)$ affects also the spatial distribution of expenditure (namely $s_{E}$ ) via differences in environmental policy

\footnotetext{
${ }^{9}$ This condition, called "non-full specialization" by Baldwin et al $(2003)$, is written as $(1-\mu)\left(E_{N}+E_{S}\right)>$ $L)$. It implies that total world spending on traditional goods is greater than the maximum value of traditional production that is possible by either region.
} 
$\left(v_{N}, v_{S}\right)$. Indeed, differences in environmental constraints determine capital's reward (relation (13)) and thus the spatial distribution of income.

On the industrial goods market, firm production in each region depends on foreign and domestic demands. From relation (10) that defines the demand function in region $i$, we can deduce the scale of production of a firm located in $\mathrm{N}$ and $\mathrm{S}$ respectively:

$$
\begin{aligned}
& x_{N}=\mu\left(\frac{E_{N}}{n_{N}+n_{S} \tau^{1-\sigma}}+\frac{E_{S} \tau^{1-\sigma}}{n_{S}+n_{N} \tau^{1-\sigma}}\right) \\
& x_{S}=\mu\left(\frac{E_{S}}{n_{S}+n_{N} \tau^{1-\sigma}}+\frac{E_{N} \tau^{1-\sigma}}{n_{N}+n_{S} \tau^{1-\sigma}}\right)
\end{aligned}
$$

The first and second terms in brackets describe respectively domestic and foreign demand.

From this, we can derive the expressions of capital's short-run reward in each region:

$$
\begin{aligned}
& \pi_{N}=\alpha\left(\frac{E_{w}}{K_{w}}\right)\left(\frac{s_{E}}{s_{n}+\left(1-s_{n}\right) \phi}+\frac{\left(1-s_{E}\right) \phi}{\left(1-s_{n}\right)+s_{n} \phi}\right)-v_{N} \\
& \pi_{S}=\alpha\left(\frac{E_{w}}{K_{w}}\right)\left(\frac{\left(1-s_{E}\right)}{\left(1-s_{n}\right)+s_{n} \phi}+\frac{s_{E} \phi}{s_{n}+\left(1-s_{n}\right) \phi}\right)-v_{S}
\end{aligned}
$$

with $\phi=\tau^{1-\sigma}, \phi \in[0,1]$ which is inversely proportional to trade costs $\tau(\phi=0$ represents autarky and $\phi=1$ free trade). To simplify notation, we use it to substitute for $\tau$ subsequently.

From (12) and (17), the long run equilibrium condition (solving $\pi_{N}=\pi_{S}$ ) can be written as:

$$
s_{E}=\frac{\left[(1-\phi)\left(2 \alpha L-\left(v_{N}-v_{S}\right) s_{n}\right)+v_{N}(1-\alpha)-v_{S}(1-\alpha \phi)\right]\left[s_{n}+\left(1-s_{n}\right) \phi\right]}{\alpha\left(1-\phi^{2}\right)\left[2 L-v_{N} s_{n}-v_{S}\left(1-s_{n}\right)\right]}
$$

Finally, we turn to the long run interaction between the global pollution level $(P)$ and the spatial distribution of industry $\left(s_{n}\right)$. Given $x_{i}=\sigma\left(\pi_{i}+v_{i}\right) \forall i=N, S$ and the definition of the long run reward to capital in (13), development of relation (4) yields:

$$
P=\frac{\sigma a\left[2 L \alpha-v_{N} s_{n}-v_{S}\left(1-s_{n}\right)\right]}{(1-\alpha)}\left[\beta_{N} s_{n}+\beta_{S}\left(1-s_{n}\right)\right]+a \sigma\left[\beta_{N} v_{N} s_{n}+\beta_{S} v_{S}\left(1-s_{n}\right)\right]
$$

The long run equilibrium of the model results from a system of 3 equations $(15,18$, $19)$ with 3 endogenous variables $\left(s_{E}, s_{n}, P\right)$. Unfortunately, the combination of (15) and (18) leads to a quadratic equation which is inconvenient to induce a tractable solution 
for $s_{n}$ (the spatial equilibrium) and $s_{E}$ (the international distribution of income across regions). Consequently, we carry out throughout the following sections an analysis in comparative statics with initially stricter environmental standards in North $\left(\beta_{N}<\beta_{S}\right)$.

\section{On the Efficiency of Unilateral Environmental Policy}

In this section, we investigate the consequences of unilateral environmental policy. More specifically, we assume that North unilaterally reinforces its environmental regulation by constraining firms located in its area to reduce their level of greenhouse gas emissions. Meanwhile, South does not modify its national environmental regulation: we are thus in a typical configuration where South follows a "passive ecological dumping". The firms located in North are then confronted with a dual choice: either meet this new environmental standard, thereby incurring an increase in their production costs, or avoid it by relocating their productive activity in South.

To keep things simple, we define a benchmark of total environmental laxism in South: that is to say, firms located in South face no pollution abatement constraint $\left(\beta_{S}=1 \Rightarrow v_{S}=0\right)$. North's unilateralism is then evaluated through comparative statics on the impact of a reduction in $\beta_{N}$.

\subsection{Relocation of industrial activities}

With $\beta_{S}=1$, relation (15) describing the market size condition is rewritten as:

$$
s_{E}=\frac{(1-\alpha)}{2 L-v_{n} s_{n}}\left(L-v_{n} s_{n} s_{K}\right)+\alpha s_{K}
$$

Given differences in incomes between North and South $\left(s_{K}>1 / 2\right)$, we show in Appendix A that this relation is negatively sloped in a diagram $\left(s_{n}, s_{E}\right)$ (Figure 1$)$. Indeed, with growing spatial agglomeration in North, more firms are subjected to strict environmental standards $\left(\beta_{N}>0\right)$, which leads to lower capital profitability. Assuming that North is abundant in capital $\left(s_{K}>1 / 2\right)$, it will be more affected by this change in factor rewards, thus explaining decrease in nominal income with spatial concentration in that region.

We also show in Appendix A that a more stringent environmental policy in North shifts the curve (20) downward to the left. A reduction in $\beta_{N}$ increases the environmental $\operatorname{cost}\left(v_{N}\right)$, which in turn lowers capital's reward $\left(\pi_{N}\right)$. As capital is mobile, this phenomenon spreads internationally. But under the assumption that North is more abundant in capital, its relative income $\left(s_{E}\right)$ will decrease for an unchanged spatial distribution of industry $\left(d s_{n}=0\right)$.

With $\beta_{S}=1$, the long run locational equilibrium condition (relation (18)) becomes:

$$
s_{E}=\frac{\left[(1-\phi)\left(2 \alpha L-v_{N} s_{n}\right)+v_{N}(1-\alpha)\right]\left[s_{n}+\left(1-s_{n}\right) \phi\right]}{\alpha\left(1-\phi^{2}\right)\left[2 L-v_{N} s_{n}\right]}
$$


It is shown in Appendix B that this relation is an upward curve in a diagram $\left(s_{n}, s_{E}\right)$ (Figure 1), describing the traditional "home market effect" in geography models: spatial agglomeration in North $\left(s_{n}\right)$ is increasing with the North's share of world expenditure $\left(s_{E}\right)$. We also show in Appendix B that a reduction in $\beta_{N}$ moves the curve leftwards: for a given distribution of income $\left(d s_{E}=0\right)$, North's stricter environmental standards will drive firms out of the region.

\section{Figure 1: The effects of unilateral environmental regulation}

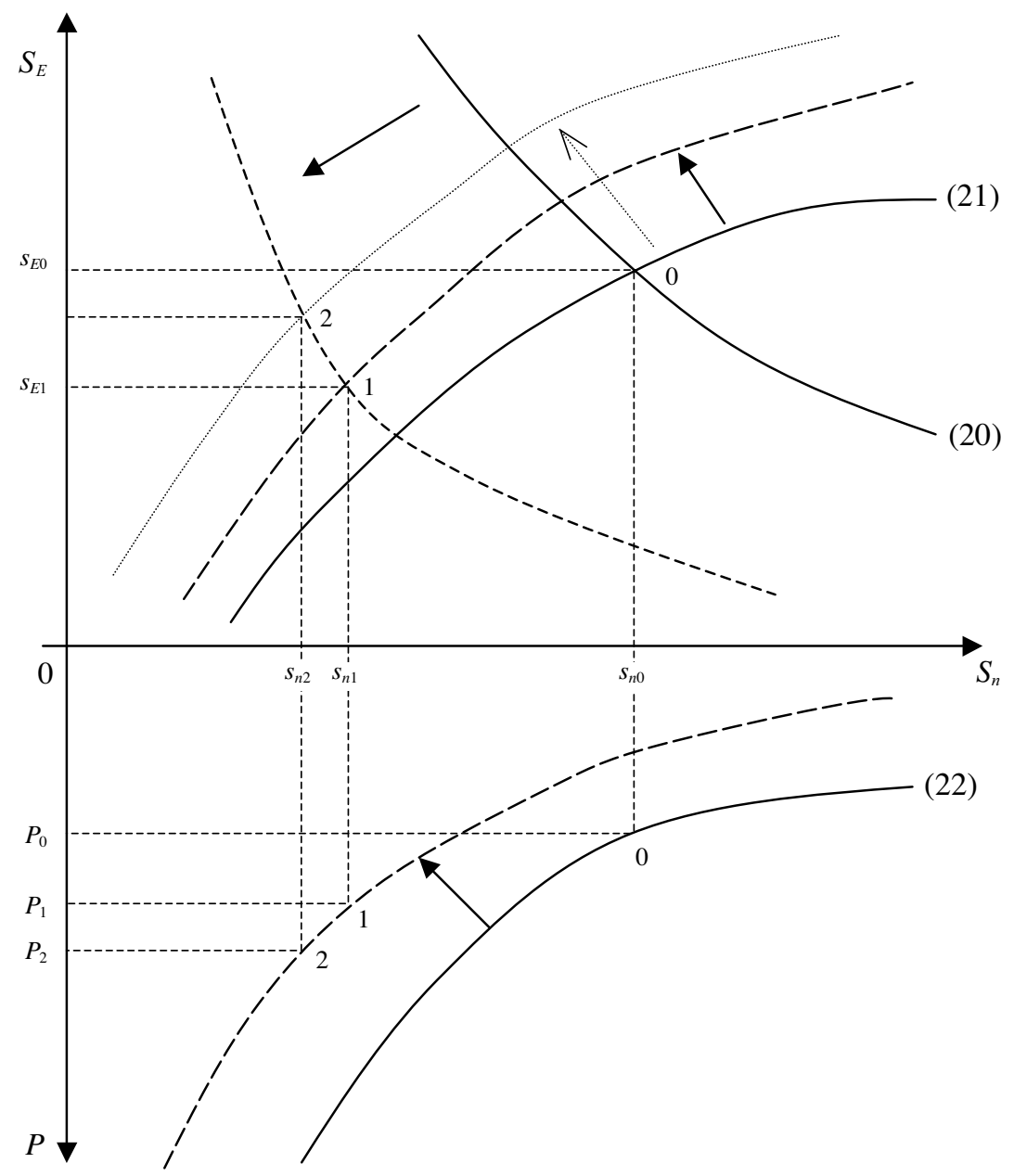

Figure 1 shows graphically that the ambitious pollution abatement policy in North, with lower $\beta_{N}$, leads to a jump from equilibrium 0 to equilibrium 1 . The unambiguous reduction in $s_{n}$ suggests that the industrial firms located in North choose to circumvent 
the environmental constraints by moving away. However, the extent of the phenomenon is downplayed by privileged access to a larger market once a firm is located in North.

At the same time, the reduction of capital's reward in North spreads internationally via firm mobility. This in turn decreases nominal income in both regions $\left(E_{N}, E_{S}\right)$ while affecting, as we showed, North more because of its capital endowment. To complete the welfare analysis, we have to consider the impact of North's unilateral environmental policy on the cost of living (price indices) in the two regions (relation (7)):

$$
G_{N}=\left[s_{n}^{1-\sigma}+\phi\left(1-s_{n}\right)^{1-\sigma}\right]^{-\mu /(\sigma-1)} \text { and } G_{S}=\left[\left(1-s_{n}\right)^{1-\sigma}+\phi s_{n}^{1-\sigma}\right]^{-\mu /(\sigma-1)}
$$

Relocation of productive activities to the South implies an increase in North's price index because more goods have to be imported, implying a higher trade cost than the one faced if the good was produced locally. In contrast, the price index decreases in South since it imports a narrower range of industrial goods. In addition, we saw that nominal income decreases in the two regions, thereby resulting unambiguously in a reduction of real income in North. The net effect of North's unilateralism on South's real income remains ambiguous, depending on the extent of industrial relocation: if this phenomenon is extensive, the price index in South will drop strongly thereby increasing the likelihood of real income improvement.

\subsection{The efficiency of unilateralism on global pollution control}

To complement our analysis, we now analyze the efficiency of unilateralism in terms of global pollution abatement.

With $\beta_{S}=1$, relation (19) defining the long run global pollution level becomes:

$$
P=\frac{\sigma a\left(2 L \alpha-v_{N} s_{n}\right)}{(1-\alpha)}\left[\beta_{N} s_{n}+\left(1-s_{n}\right)\right]+\sigma v_{N} a \beta_{N} s_{n}
$$

As drawn in Figure 1, we show in Appendix $C$ that this relation is a downward curve in a diagram $\left(s_{n}, P\right)$ : a higher $s_{n}$ increases the number of firms forced to exploit a cleaner technology, which leads to lower global pollution. In the same way, we also show in Appendix C that a lower $\beta_{N}$ shifts the curve (22) leftwards: regardless of what happens to industry location (unchanged $s_{n}$ ), stricter environmental standards in North will reduce transboundary pollution $(P)$.

Turning to the efficiency of North's unilateral environmental policy, it can be seen in Figure 1 that the outcome is ambiguous: in particular, there is a trade-off between relocation of firms $\left(\Delta s_{n}\right)$ and the shift in the global pollution schedule (curve (22)). The ambiguity of the environmental impact can be seen analytically: relying on relation (22), we can show that the change in $P$ with respect to a small change in $\beta_{N}$ is decomposed into three interacting elements denoted respectively the technology effect, the scale effect and the relocation effect. 


$$
\frac{d P}{d \beta_{N}}=\underbrace{\left.\frac{\partial P}{\partial \beta_{N}}\right|_{d s_{n}=d v_{N}=0}}_{\text {technology effect }}+\underbrace{v_{N}^{\prime} \times\left.\frac{\partial P}{\partial v_{N}}\right|_{d s_{n}=d \beta_{N}=0}}_{\text {scale effect }}+\underbrace{\frac{\partial s_{n}}{\partial \beta_{N}} \times \frac{d P}{d s_{n}}}_{\text {relocation effect }}
$$

- The technology effect describes the favorable impact on environment of cleaner industrial processes. Relying on relation (14), we show that the first partial derivative in (23) is positive:

$$
\left.\frac{\partial P}{\partial \beta_{N}}\right|_{d s_{n}=d v_{N}=0}=\sigma a s_{n}\left[\left(\frac{2 L \alpha-v_{N} s_{N}}{(1-\alpha)}\right)+v_{N}\right]>0
$$

Cleaner technology used in North implies, all other things being equal (ie for a given spatial distribution of industry and a given environmental cost), a lower level of global pollution.

- The scale effect measures the impact of the environmental policy on firm scale which in turn determines the level of pollution. According to relation (23), this effect is decomposed into two terms. The first one asserts that a lower $\beta_{N}$ raises the environmental cost of firms located in North $\left(v_{N}^{\prime}<0\right)$. But, according to the second term, the higher fixed cost affects firm scale and the induced level of P. Relying on (4) and assuming that $\beta_{S}=1$, we can decompose this second term further:

$$
\left.\frac{\partial P}{\partial v_{N}}\right|_{d s_{n}=d \beta_{N}=0}=a\left[\left.s_{n} \beta_{N} \frac{\partial x_{N}}{\partial v_{N}}\right|_{d s_{n}=0}+\left.\left(1-s_{n}\right) \frac{\partial x_{s}}{\partial v_{N}}\right|_{d s_{n}=0}\right]
$$

To study this derivative in more detail, we have to distinguish the scale of firms located in North and South. After rewriting (3) and (11), we can observe that $x_{N}=\sigma\left(\pi_{N}+v_{N}\right)$ and $x_{S}=\sigma \pi_{S}$. In the long run, capital's rewards are equalized across regions and relation (13) indicates that $\pi_{N}=\pi_{S}=\pi^{*}=\left(2 \mathrm{~L} \alpha-v_{N} s_{n}\right) /(1-\alpha)$. In the long run, we have thus $x_{N}>x_{S}$ as firms located in North seek to cover the additional fixed cost by producing at larger scale (we will name this the "paying off" effect). At the same time, the higher environmental cost in North burdens capital profitability on global markets (via capital mobility) and hence encourages firms in both regions to reduce their scale of production (we refer to this as the "capital profitability" effect). These two effects induced by the increase in $v_{N}$ jointly determine the scale of firms located in North:

$$
\left.\frac{\partial x_{N}}{\partial v_{N}}\right|_{d s_{n}=0}=\sigma\left[\left.\frac{\partial \pi_{N}}{\partial v_{N}}\right|_{d s_{n}=0}+1\right]=\frac{\sigma}{1-\alpha}\left[\left(1-s_{n}\right)-\alpha\right]
$$

In the first expression of (26) we find our two above effects in square brackets: the first term refers to the capital profitability effect (the sign of the partial derivative 
is negative) whereas the second, of positive sign, refers to the paying off effect. The second expression on the right-hand side shows that the interaction between these two effects renders the sign of (26) ambiguous.

In contrast, such ambiguity disappears for the firms located in South. As they are not affected directly by the environmental constraint, only the capital profitability effect prevails (via the international mobility of capital) so that the impact of $v_{N}$ on their scale of production is negative.

$$
\left.\frac{\partial x_{s}}{\partial v_{N}}\right|_{d s_{n}=0}=\left.\sigma \frac{\partial \pi_{N}}{\partial v_{N}}\right|_{d s_{n}=0}=-\frac{\sigma s_{n}}{1-\alpha}<0
$$

Substituting expressions (26) and (27) into (25), we obtain:

$$
\left.\frac{\partial P}{\partial v_{N}}\right|_{d s_{n}=d \beta_{N}=0}=\frac{\sigma a}{1-\alpha}\left[s_{n}\left(1-s_{n}\right)\left(\beta_{N}-1\right)-\alpha s_{n} \beta_{N}\right]<0
$$

The increase of the environmental cost in North involves, all things being equal (holding the distribution of industrial activity and the emission coefficient in North constant), a reduction in the level of global pollution via a negative supply effect. Because of capital mobility, firms in both regions are affected by the capital profitability effect ${ }^{10}$ and lower their scale of production. In contrast, only firms located in North are subject to the paying off effect, which induces production at a larger scale. We can see that the capital profitability effect dominates this interacting process.

- Contrary to the two former effects, the relocation effect affects negatively expression (23):

$$
\frac{\partial s_{n}}{\partial \beta_{N}} \times \frac{d P}{d s_{n}}<0
$$

The relocation effect allows us to assert that the efficiency of a unilateral environmental policy can be cancelled by firm mobility: instead of applying a cleaner production process which by nature is more expensive, firms located in North can be sensitive to South's laxer environmental standards.

All in all, relation (23) which measures the consequences of North's unilateral environmental policy focuses on the interaction of three contradictory effects. Whereas the technology and the scale effects intervene positively on environment, by contrast the relocation effect hampers the efficiency of such ambitious environmental policy. Any event affecting the interaction between these three effects will modify the ecological consequences of Northern unilateralism.

\footnotetext{
${ }^{10}$ More precisely, as shown by relation (25), the capital profitability effect is weighted in each region by its respective emission coefficient and share of industrial firms.
} 


\subsection{The consequences of globalization}

Considering our focus which is the analysis of international environmental issues and firm location, we investigate here the consequences of globalization on the efficiency of unilateral pollution controls. Are the effects of environmental regulation the same whatever the degree of trade integration? By reducing barriers to trade in industrial goods, globalization of the world economy affects the interactions at work and the consequent impact on global pollution. This process is captured in our model by the parameter $\phi(0<\phi<1)$ which measures the freeness of trade.

We can observe from relation (21) that:

$$
\left.\frac{\partial^{2} s_{E}}{\partial \beta_{N} \partial \phi}\right|_{d s_{n}=0}=\left.v_{N}^{\prime} \frac{\partial^{2} s_{E}}{\partial v_{N} \partial \phi}\right|_{d s_{n}=0}<0
$$

Expression (29) is drawn in Figure 1 as follows: globalization illustrated by a higher $\phi$ magnifies the shift of the curve (21) onto the left which corresponds to a reduction in $\beta_{N}$. The new equilibrium 2 is characterized inter alia by a stronger reduction in $s_{n}$ compared to equilibrium 1 . This phenomenon arises because globalization makes access to North's market easier and hence firms more sensitive in their location choice to the induced pollution abatement overcost. As spatial agglomeration in North in order to benefit from the market size effect will be reduced, it becomes more profitable for firms to relocate to South and serve North's larger market through exports instead of complying with its local environmental standards.

In other words, the globalization process enhances firm sensitivity to "ecological dumping" and change consequently the efficiency of national policy instruments. As can be seen in Figure 1, globalization magnifies the relocation effect (relation (23)) and increases the probability that North's pollution abatement policy paradoxically harms the environment.

\section{World Harmonization of Environmental Standards}

Our results in the preceding sections emphasizing the inefficiency of unilateral policy with regard to international environmental issues point to a more general conclusion: the efficient management of global public goods requires harmonization of environmental policies at the international level. Consequently, we reformulate our model in comparative statics: departing from the benchmark where South is characterized by lax environmental standards $\left(\beta_{S}=1,0<\beta_{N}<1\right)$, we now constrain South to adopt the same stringent environmental standards as North $\left(\beta_{S}=\beta_{N}\right)$. For an analysis of the locational equilibrium under harmonized environmental regulations, we rewrite the basic model (Section 2) by holding: $\beta_{S}=\beta_{N}=\beta$ and $v_{S}=v_{N}=v$.

Relation (15) describing the market size condition is then rewritten as:

$$
s_{E}=\frac{(1-\alpha)}{2 L-v}\left(L-v s_{K}\right)+\alpha s_{K}
$$


In contrast to (20), we can see that the relative distribution of world income $\left(s_{E}\right)$ becomes now invariant to the spatial distribution of industry $\left(s_{n}\right)$ (Figure 2). This outcome can be explained by the fact that harmonization of the environmental standards cancels short run differences in capital's rates of return across regions. Hence, as capital's reward is repatriated to the country of origin, reallocation of industry induces no income change in the two regions. ${ }^{11}$

In comparison with the benchmark $\left(\beta_{S}=1,0<\beta_{N}<1\right)$, we show in Appendix A that a cleaner environment in South (reduction in $\beta_{S}$ ) shifts the curve (20) downward to the left. Such a displacement suggests, all things being equal, relocation of industry to South: with international mobility of capital, an increase in South's environmental $\operatorname{cost}\left(v_{S}\right)$ erodes capital profitability in both regions. But as North is more endowed with capital, this region will be more affected by the lower reward to capital and the induced world income redistribution (decrease in $s_{n}$ ).

${ }^{11}$ Relation (30) refers to the case $s_{n}=1$ in expression (20), ie all industrial activities are fully agglomerated in the region adopting clean technology. 


\section{Figure 2: International harmonization of environmental regulations}

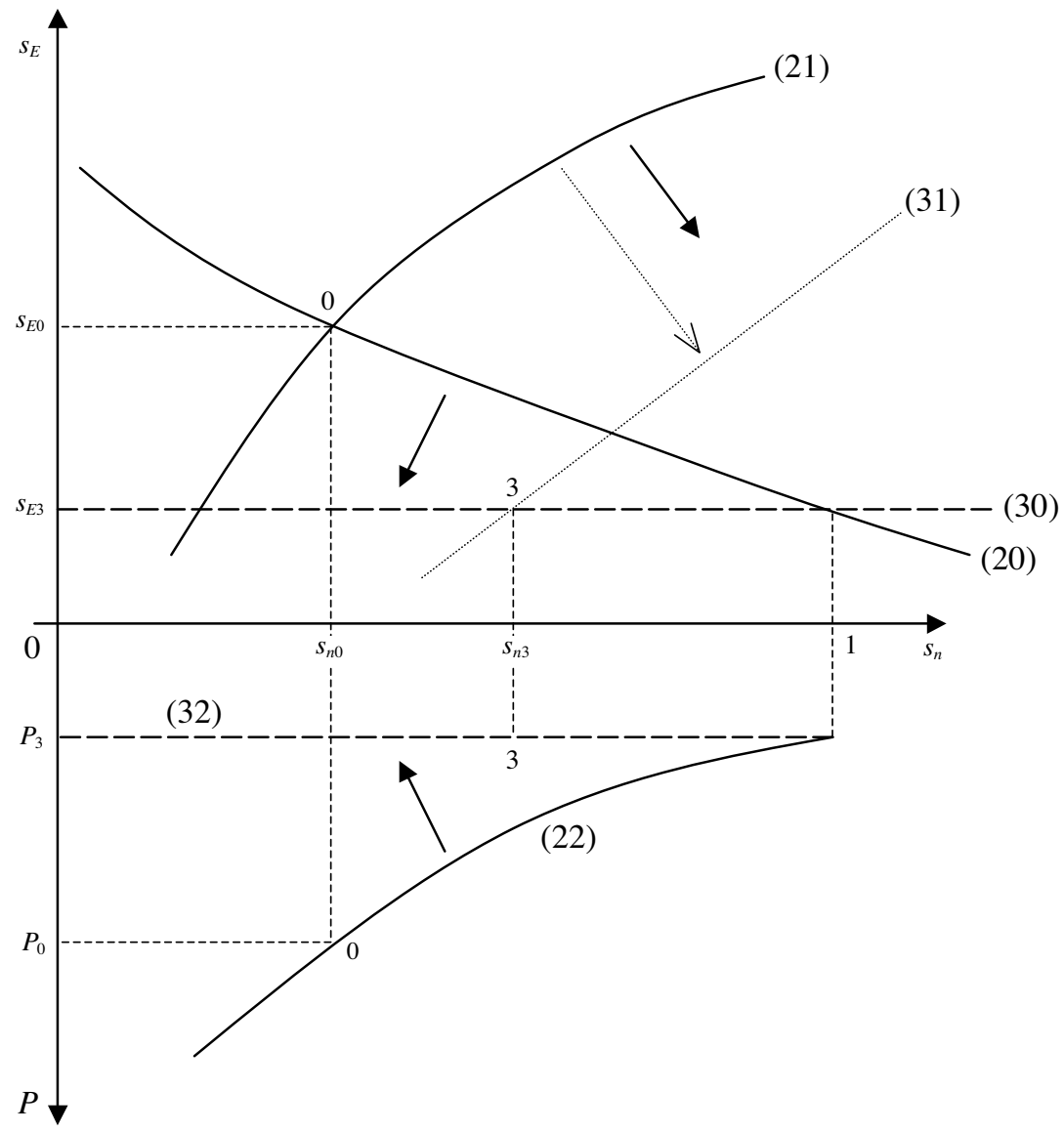

With harmonized environmental standards, spatial equilibrium condition (18) becomes:

$$
s_{E}=\frac{s_{n}+\left(1-s_{n}\right) \phi}{(1+\phi)}
$$

In comparison with the benchmark, we show in Appendix B that environmental harmonization through reduction in $\beta_{S}$ shifts the spatial equilibrium schedule (curve (21)) downward onto the right ${ }^{12}$. Such a displacement means that the increase in the environmental fixed cost $\left(v_{S}\right)$ encourages, all things being equal, relocation of firms to North (increase in $s_{n}$ ).

${ }^{12}$ We find the same locational equilibrium condition as in Baldwin et al (2003). In reference to the benchmark, relation (31) would correspond to the particular case $v_{N}=0$. 
All in all, stricter pollution controls in South lead to two contradictory forces at work:

1) A direct relocation effect. Faced to increased production costs, firms located in South choose to circumvent the environmental constraint by moving away (higher $s_{n}$ with displacement of (21)).

2) An indirect relocation effect. By spreading internationally, the eroding capital profitability implies world income redistribution and a relative market size effect which paradoxically increase South's attractiveness (decrease in $s_{n}$ with displacement of (20)).

The final outcome seems a priori ambiguous. However, we can show that the globalization process may intensify the direct effect while keeping unchanged the indirect effect. Indeed, a higher $\phi$ does not affect the market size condition (relation (30)) while it magnifies the shift of the curve (21) onto the right (relation (31)). A deeper look at relation (18) allows us to verify analytically that:

$$
\left.\frac{\partial^{2} s_{E}}{\partial \beta_{S} \partial \phi}\right|_{d s_{n}=0}=\left.v_{S}^{\prime} \frac{\partial^{2} s_{E}}{\partial v_{S} \partial \phi}\right|_{d s_{n}=0}>0
$$

Similar to the previous scenario, globalization enhances firm sensitivity to cost differentials. However, in case of international harmonization with higher environmental standards, this option hurts specifically the Southern region through a relocation process.

In the cooperative scenario, the level of transboundary pollution becomes independent from the location decisions of firms. Indeed, relation (19) is rewritten with $\beta_{S}=\beta_{N}=\beta$ :

$$
P=\frac{\sigma a \alpha \beta(2 L-v)}{(1-\alpha)}
$$

Also in comparison with the benchmark, relation (32) determines minimal pollution in a non-cooperative situation where all industrial activities would be agglomerated in North ((32) corresponds to relation (22) with $\left.s_{n}=1\right)$.

Figure 2 depicts the efficiency of international cooperative policy when globalization proceeds. By the jump from equilibrium 0 to equilibrium 3, we can see that harmonization of the environmental standards may be efficient in terms of global pollution abatement. But it may induce simultaneously relocation of industry in favor of North: within an integrated world economy with identical environmental fixed cost in both regions, firms will prefer to benefit from a better access to the region with the largest market.

Finally, turning to the welfare effects, recall that the higher environmental cost in South reduces reward to capital internationally via capital mobility. As we showed, this reduction affects North's nominal income more because of its higher capital endowment. However, its price index tends to decrease with the attraction of industrial activities, implying an ambiguous outcome on real income: the decrease in the price index $\left(G_{N}\right)$ may prevail over the reduction of nominal income $\left(E_{N}\right)$. In contrast, South's disindustrialization through firm relocation affects its price index in the opposite direction: as a wide range of industrial goods are now imported, it bears higher 
trade costs. Accordingly, harmonization of the environmental standards in the age of globalization implies unambiguously a reduction of real income in South.

\section{Conclusion}

In this paper, we have attempted to develop a theoretical analysis of environmental issues in an economic geography model. Such a framework enables us to evaluate environmental policy in a context of international factor mobility and growing interdependence between individual nations. We have first considered a unilateral environmental policy adopted by the developed region. It is shown in particular that the latter undergoes a phenomenon of industrial relocation with a fall in its real income. Our theoretical findings are partly consistent with the pollution haven effect which points to the negative impact of stricter environmental regulation on the location of firms. However, the ecological dumping argument has only found partial theoretical support because even though North reinforces its environmental constraint, it still remains attractive as firms can take advantage of its relative market size. Meanwhile, the efficiency of unilateralism in terms of global pollution abatement is ambiguous. This outcome can be explained by the fact that the environmental policy generates three effects which work in opposite directions. The technology and the scale effects jointly reduce global pollution whereas the relocation effect works against it. It is shown in our model that globalization enhances firm sensitivity to ecological dumping and magnifies the relocation effect. In consequence, North's ambitious pollution abatement policy may paradoxically harm the environment.

These outcomes of unilateral management of global public goods provide quite natural arguments for harmonization of environmental regulations. However, although it is widely agreed that there is an important need for international cooperation, the outcomes remains uneven when globalization is considered: environmental harmonization hurts specifically South both in terms of spatial distribution of industry and real income. In other words, South would "unilaterally" incur the burden of a successful harmonized environmental policy as globalization proceeds. These outcomes bring theoretical support to the so-called principle of "common but differentiated responsibilities" between North and South. More specifically, it raises the urgent challenge of financial and technological compensations that developed countries should grant to developing countries in support of multilateral environmental agreements. 


\section{Appendix A: The properties of the market size condition}

Relation (15) defines the market size condition:

$$
s_{E}=\frac{(1-\alpha)}{2 L-v_{N} s_{n}-v_{S}\left(1-s_{n}\right)}\left(L-v_{N} s_{n} s_{K}-v_{S} s_{K}\left(1-s_{n}\right)\right)+\alpha s_{K}
$$

Assuming North-South asymmetry with $s_{K}>1 / 2$ and $v_{N}>v_{S}$, we can show that relation (15) is negatively sloped in a diagram $\left(s_{n}, s_{E}\right)$ :

$$
\frac{d s_{E}}{d s_{n}}=\frac{(1-\alpha)\left(v_{N}-v_{S}\right)\left[L\left(-2 s_{K}+1\right)\right]}{\left(2 L-v_{N} s_{n}-v_{S}\left(1-s_{n}\right)\right)^{2}}<0
$$

With $s_{K}>1 / 2$ and $v_{N}>v_{S}$, stricter environmental regulations either in North or in South (reduction in $\beta_{N}$ or $\beta_{S}$ ) shift the curve (15) downward to the left as we have respectively:

$$
\begin{aligned}
& \left.\frac{\partial s_{E}}{\partial \beta_{N}}\right|_{d s_{n}=0}=\frac{v_{N}^{\prime}(1-\alpha) s_{n}\left[L\left(-2 s_{K}+1\right)\right]}{\left(2 L-v_{N} s_{n}-v_{S}\left(1-s_{n}\right)\right)^{2}}>0 \\
& \left.\frac{\partial s_{E}}{\partial \beta_{S}}\right|_{d s_{n}=0}=\frac{v_{S}^{\prime}(1-\alpha)\left(1-s_{n}\right)\left[L\left(-2 s_{K}+1\right)\right]}{\left(2 L-v_{N} s_{n}-v_{S}\left(1-s_{n}\right)\right)^{2}}>0
\end{aligned}
$$

\section{Appendix B: The properties of the locational equilibrium condition}

Relation (18) defines the locational equilibrium condition:

$$
s_{E}=\frac{\left[(1-\phi)\left(2 \alpha L-\left(v_{N}-v_{S}\right) s_{n}\right)+v_{N}(1-\alpha)-v_{S}(1-\alpha \phi)\right]\left[s_{n}+\left(1-s_{n}\right) \phi\right]}{\alpha\left(1-\phi^{2}\right)\left[2 L-v_{N} s_{n}-v_{S}\left(1-s_{n}\right)\right]}
$$

We then have:

$$
\begin{aligned}
& \frac{d s_{E}}{d s_{n}}=\frac{(1-\phi)}{\alpha(1+\phi)}+\frac{(1-\alpha) Z}{\alpha\left(v_{N} s_{n}+v_{S}\left(1-s_{n}\right)-2 L\right)^{2}\left(1-\phi^{2}\right)} \\
& \frac{d^{2} s_{E}}{d s_{n}^{2}}=\frac{-2 \alpha\left(v_{N}-v_{S}\right)\left(1-\phi^{2}\right)\left(v_{N} s_{n}+v_{S}\left(1-s_{n}\right)-2 L\right)(1-\alpha) Z}{\alpha^{2}\left(v_{N} s_{n}+v_{S}\left(1-s_{n}\right)-2 L\right)^{4}\left(1-\phi^{2}\right)^{2}}
\end{aligned}
$$


with $Z=(1-\phi)^{2}\left(2 L-v_{S}\right)\left(v_{N}-2 L\right)+\phi\left(v_{N}-v_{S}\right)^{2}$

Let us consider two situations:

1) if $Z>0$ then following relation (14): $d s_{E} / d s_{n}>0$ and $d^{2} s_{E} / d s_{n}^{2}>0$

2) if $Z<0$ then $d^{2} s_{E} / d s_{n}^{2}<0$. In order to determine the sign of $d s_{E} / d s_{n}$, we solve $\overline{s_{n}}$ such as $d s_{E} / d s_{n}=0$ :

$$
\overline{s_{n}}=\frac{[-(1-\alpha) Z]^{1 / 2}}{(1-\phi)\left(v_{N}-v_{S}\right)}+\frac{2 L-v_{S}}{v_{N}-v_{S}}
$$

Relying on (14) and $0<\alpha<1$, we can deduce that $2 L-v_{S} \geq v_{N}-v_{S}$, so that $\overline{s_{n}}>1 \forall 0 \leq s_{n} \leq 1$. As $\overline{s_{n}}>1$ and $d^{2} s_{E} / d s_{n}^{2}<0$ we thus have $d s_{E} / d s_{n}>0, \forall 0 \leq s_{n} \leq 1$.

We also demonstrate that more stringent environmental policy in North (reduction in $\beta_{N}$ ) moves the curve (18) leftwards:

$$
\left.\frac{\partial s_{E}}{\partial \beta_{N}}\right|_{d s_{n}=0}=\frac{(1-\alpha)\left(2 L-v_{S}\right) v_{N}^{\prime}\left[s_{n}+\left(1-s_{n}\right) \phi\right]\left[1-s_{n}(1-\phi)\right]}{\alpha\left(2 L-v_{N} s_{n}-v_{S}\left(1-s_{n}\right)\right)^{2}\left(1-\phi^{2}\right)}<0
$$

Conversely, if South imposes a reduction in $\beta_{S}$, the curve (18) moves downward onto the right:

$$
\left.\frac{\partial s_{E}}{\partial \beta_{S}}\right|_{d s_{n}=0}=\frac{(\alpha-1)\left(2 L-v_{N}\right) v_{S}^{\prime}\left[s_{n}+\left(1-s_{n}\right) \phi\right]\left[1-s_{n}(1-\phi)\right]}{\alpha\left(2 L-v_{N} s_{n}-v_{S}\left(1-s_{n}\right)\right)^{2}\left(1-\phi^{2}\right)}>0
$$

\section{Appendix C: The properties of the global pollution level}

Relation (19) defines the long run level of global pollution:

$$
P=\frac{\sigma a\left[2 L \alpha-v_{N} s_{n}-v_{S}\left(1-s_{n}\right)\right]}{(1-\alpha)}\left[\beta_{N} s_{n}+\beta_{S}\left(1-s_{n}\right)\right]+a \sigma\left[\beta_{N} v_{N} s_{n}+\beta_{S} v_{S}\left(1-s_{n}\right)\right]
$$

We can deduce that relation (19) is a downward curve in a diagram $\left(s_{n}, P\right)$ :

$$
\frac{d P}{d s_{n}}=\left(\frac{\sigma a}{(1-\alpha)}\right)\left[\begin{array}{c}
-\left(v_{N}-v_{S}\right)\left(\beta_{N} s_{n}+\beta_{S}\left(1-s_{n}\right)\right)+\left(2 l \alpha-v_{N} s_{n}-v_{S}\left(1-s_{n}\right)\right)\left(\beta_{N}-\beta_{S}\right) \\
+(1-\alpha)\left(\beta_{N} v_{N}-\beta_{S} v_{S}\right)
\end{array}\right]<0
$$

Two situations are also considered here:

1) if $\beta_{N} v_{N}-\beta_{S} v_{S}<0$ then $d P / d s_{n}<0$ 
$2)$ if $\beta_{N} v_{N}-\beta_{S} v_{S}>0$ then $(1-\alpha)\left(\beta_{N} v_{N}-\beta_{S} v_{S}\right)<\beta_{N} v_{N}-\beta_{S} v_{S}<\beta_{N}\left(v_{N}-v_{S}\right)$

Relying on the latter expression, we demonstrate that:

$\frac{d P}{d s_{n}}<\left(\frac{\sigma a}{(1-\alpha)}\right)\left[\left(\beta_{N}-\beta_{S}\right)\left[\left(v_{N}-v_{S}\right)\left(1-s_{n}\right)+\left(2 l \alpha-v_{N} s_{n}-v_{S}\left(1-s_{n}\right)\right)\right]\right]<0$

Hence, $d P / d s_{n}<0$

We can also show that cleaner environment in North (reduction in $\beta_{N}$ ) shifts the curve (19) leftwards:

$\left.\frac{\partial P}{\partial \beta_{N}}\right|_{d s_{n}=0}=\left(\frac{\sigma a s_{n}}{(1-\alpha)}\right)\left[-v_{N}^{\prime}\left(\left(1-s_{n}\right)\left(\beta_{S}-\beta_{N}\right)+\beta_{N} \alpha\right)+\left(2 L \alpha-v_{N} s_{n}-v_{S}\left(1-s_{n}\right)\right)+v_{N}(1-\alpha)\right]>0$

\section{References}

Antweiler, W., B.R. Copeland and M.S. Taylor, 2001, "Is Free Trade Good for the Environment?", The American Economic Review 91(4), 877-908.

Baldwin, R., R. Forslid, P. Martin, G. Ottaviano and F. Robert-Nicoud, 2003, Economic Geography and public Policy (Princeton University Press: Princeton, New Jersey).

Baumol, W.J. and W.E. Oates, 1971, "The Use of Standards and Prices for the Protection of the Environment", The Swedish Journal of Economics 73, 42-54.

Chiroleu-Assouline M., L. Ragot and K. Schubert, 2003, "Incentive to innovate in a Clean Technology under Monopolistic Competition: A Comparison of Policy Instruments", mimeo, University of Paris 1.

Copeland, B.R. and M.S.Taylor, 1994, "North-South Trade and the Environment", Quarterly Journal of Economics 109, 755-787.

Copeland, B.R. and M.S. Taylor, 1995, “Trade and Transboundary Pollution”, American Economic Review 85, 716-737.

Copeland, B.R. and M.S. Taylor, 1997, “A Simple Model of Trade, Capital Mobility, and the Environment", NBER Working Paper No5898, National Bureau of Economic Research.

Copeland B.R., and M.S. Taylor, 2004, "Trade, Growth and the Environment", Journal of Economic Literature 42, 7-71.

Grossman, G.M. and A.B. Krueger, 1993, "Environmental Impacts of a North American Free Trade", in: P.M. Garber, eds., The Mexico-US Free Trade Agreement, (MIT Press: Cambridge MA), 13-56.

Krugman, P.R., 1991, "Increasing returns and economic geography”, Journal of Political Economy 99, 483-499.

Krugman, P.R. and A.J. Venables, 1995, "Globalization and the inequality of nations", Quarterly Journal of Economics 110, 857-880.

Low, P. and A. Yeats, 1992, “Do Dirty Industries Migrate?”, in: P. Low, eds., International Trade and the Environment, World Bank Discussion Papers, vol. 159, 89-103. 
Mani, M. and D. Wheeler, 1999, "In Search of Pollution Havens? Dirty Industry in the World Economy", World Bank Discussion Paper $n^{\circ} 402$, World Bank: Washington DC, $115-128$.

Martin, P. and C.A. Rogers, 1995, "Industrial Location and Public Infrastructure", Journal of International Economics 39, 335-351.

Pflüger, M., 2001, "Ecological Dumping under Monopolistic Competition", Scandinavian Journal of Economics 103(4), 689-706.

Rauscher, M., 1995, "Environmental Regulation and the Location of Polluting Industries", International Tax and Public Finance 2(2), 229-244.

Ulph, A.,1996a, "Environmental Policy and International Trade when Government and Producers act Strategically", Journal of Environmental Economics and Management 30, 265-281.

Ulph, A., 1996b, "Environmental Policy Instruments and Imperfectly Competitive International Trade", Environmental and Resource Economics 7(4), 333-355.

Ulph, A., 1997, "Environmental Policy and International Trade. A Survey of Recent Economic Analysis", in: H. Folmer and T. Tietenberg, eds., The International Yearbook of Environmental and Resource Economics 1997/1998: A Survey of Current Issues, (Edward Elgar: Cheltenham, UK), 205-242.

Wilson, J.D., 1996, "Capital Mobility and Environmental Standards: Is There a Theoretical Basis for a Race to the Bottom?", in: J.N. Bhagwati and R.E. Hudec, eds., Fair Trade and harmonization, Vol. 1 (MIT Press: Cambridge MA), 393-428.

Zeng, D.Z. and L. Zhao, 2006, "Pollution Havens and Industrial Agglomeration", Discussion Paper, No.197, Kobe University. 